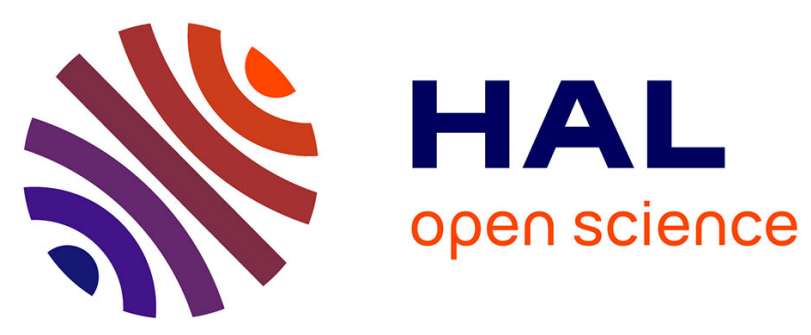

\title{
Large-Scale Additive Manufacturing of Ultra-High-Performance Concrete of Integrated Formwork for Truss-Shaped Pillars
}

Nadja Gaudillière, Romain Duballet, Charles Bouyssou, Alban Mallet, Philippe Roux, Mahriz Zakeri, Justin Dirrenberger

\section{To cite this version:}

Nadja Gaudillière, Romain Duballet, Charles Bouyssou, Alban Mallet, Philippe Roux, et al.. LargeScale Additive Manufacturing of Ultra-High-Performance Concrete of Integrated Formwork for TrussShaped Pillars. Robotic Fabrication in Architecture, Art and Design 2018, Springer International Publishing, pp.459-472, 2018, 9783319922942. 10.1007/978-3-319-92294-2_35. hal-01904661

\section{HAL Id: hal-01904661 https://hal.science/hal-01904661}

Submitted on 21 Dec 2018

HAL is a multi-disciplinary open access archive for the deposit and dissemination of scientific research documents, whether they are published or not. The documents may come from teaching and research institutions in France or abroad, or from public or private research centers.
L'archive ouverte pluridisciplinaire HAL, est destinée au dépôt et à la diffusion de documents scientifiques de niveau recherche, publiés ou non, émanant des établissements d'enseignement et de recherche français ou étrangers, des laboratoires publics ou privés. 


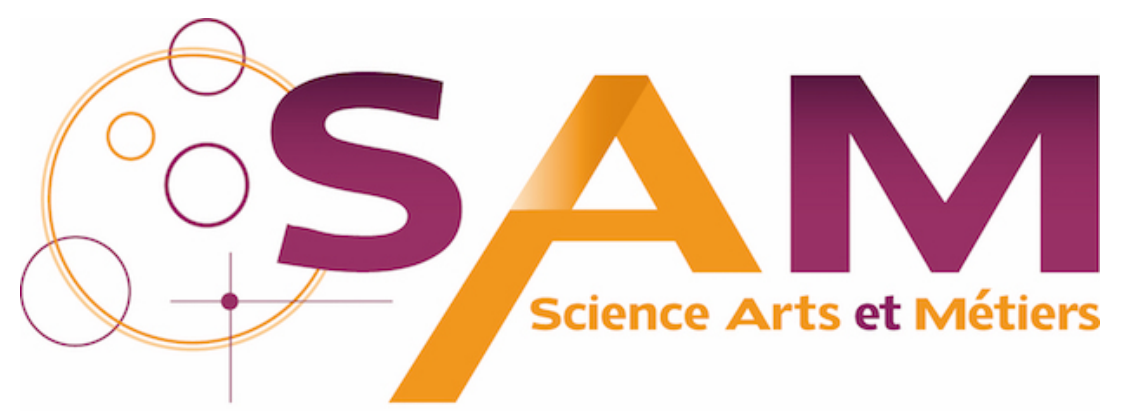

Archive Ouverte - Open Repository

\section{Science Arts \& Métiers (SAM)}

is an open access repository that collects the work of Arts et Métiers ParisTech researchers and makes it freely available over the web where possible.

This is an author-deposited version published in: https://sam.ensam.eu Handle ID: .http://hdl.handle.net/10985/13839

\section{To cite this version :}

Nadja GAUDILLIÈRE, Romain DUBALLET, Charles BOUYSSOU, Alban MALLET, Philippe ROUX, Mahriz ZAKERI, Justin DIRRENBERGER - Large-Scale Additive Manufacturing of UltraHigh-Performance Concrete of Integrated Formwork for Truss-Shaped Pillars - 2018 


\title{
Large-Scale Additive Manufacturing of Ultra-High-Performance Concrete of Integrated Formwork for Truss-Shaped Pillars
}

\author{
Nadja Gaudillière $^{1,2(凶)}$, Romain Duballet ${ }^{1,3}$, Charles Bouyssou ${ }^{1}$, \\ Alban Mallet ${ }^{1}$, Philippe Roux ${ }^{1}$, Mahriz Zakeri $^{1}$, \\ and Justin Dirrenberger ${ }^{1,4}$ \\ 1 XtreeE, 18-20 rue du Jura, CP 40502, 94623 Rungis, France \\ nadja.gaudilliere@gmail.com \\ 2 Laboratoire GSA, Ecole Nationale Supérieure d'Architecture Paris-Malaquais, \\ 75006 Paris, France \\ ${ }^{3}$ Laboratoire Navier, UMR 8205, Ecole des Ponts, IFSTTAR, CNRS, UPE, \\ 77455 Champs-sur-Marne, France \\ ${ }^{4}$ Laboratoire PIMM, Arts et Métiers-ParisTech, Cnam, CNRS, UMR 8006, \\ 75013 Paris, France
}

\begin{abstract}
In the present paper a new additive manufacturing processing route is introduced to produce ultra-high-performance concrete complex architectonic elements, by printing integrated formwork. Interdisciplinary work involving material science, computation, robotics, architecture and design resulted in the development of an innovative way of $3 \mathrm{D}$ printing cementitious materials. The $3 \mathrm{D}$ printing process involved is based on a FDM-like technique, in the sense that a material is deposited layer by layer through an extrusion printhead mounted on a 6-axis robotic arm. An architectural application is used as a case-study to demonstrate the potentialities of the technology. Along with the detailed description of the design and construction process, a description of the responsibilities and their distribution amongst the stakeholders involved in the project is given. The steps taken to include the 3D printed element in an authorized regulatory context are presented as well. The structural elements produced constitute some of the largest 3D printed concrete parts available until now. Multi-functionality was enabled for structural elements by taking advantage of the complex geometry which can be achieved using our technology for large-scale additive manufacturing. The proposed process succeeds in solving several of the current issues problems that can be found in the production of 3D printed architectural features for an AEC industrial context and therefore suggests an immediately viable route for industry assimilation.
\end{abstract}

Keywords: 3D printing $\cdot$ Concrete $\cdot$ Cementitious materials Large-scale additive manufacturing $\cdot$ Architecture $\cdot$ Design Truss-shaped pillars 


\section{Introduction}

Until recently, additive manufacturing (AM) techniques were confined to high value adding sectors such as the aeronautical and biomedical industries, mainly due to the steep cost of primary materials used for such processes. In the last decade, the development of large-scale AM in such domains as design, construction and architecture, using various materials such as polymers, metal, and cementitious materials, has surged.

Historically, the first attempt at cement-based AM was made by Pegna [12] using an intermediate process between the classical powder bed and inkjet head 3D printing (3DP) [14] and fused deposition modelling (FDM) [5], in order to glue sand layers together with a Portland cement paste. Many groups have been involved with the development of large-scale AM for construction applications, all of which have been using processing routes derived from FDM or 3DP, although varying depending on the chosen material and targeted application.

Three pioneering technologies can be mentioned regarding cement-based AM. Contour Crafting technology [11] is based on a printhead mounted on a crane, extruding simultaneously two layers of material intended to be used as formwork. The main drawbacks of Contour Crafting technology are its limitation to vertical extrusion and a complex implementation of the system for industrial production. Loughborough University concrete printing technology [2], using a similar system with a printing nozzle and a crane, uses a material with higher performances and to a small extrudate, allowing a good geometrical control. However, the printing process is relatively slow and the use of an overhead crane both discourages the printing of complex geometries and complicates the industrial development. Finally, D-Shape technology [4] consists in a large-scale sandbed locally solidified by deposition of a binding agent, layer by layer. Although designed for off-site production of prefabricated elements, D-Shape technology currently aims to demonstrate the feasibility of the process on-site. More detailed information regarding existing cement-based AM techniques can be found in the literature $[3,7]$.

In the past few years, several other technologies have been developed for cementbased AM techniques and applications in construction, both by university research groups and new industrial players. Landmarks of AM construction applications have been produced during this same period, such as housing printed by the Chinese company Winsun and other small-scale building printed by companies such as Apis Cor (Russia) or CyBe (Holland). Major achievements also include two bridges, one by Acciona in Madrid and the other by TU Eindhoven in the Netherlands.

Beyond the mention in the Contour Crafting patent of the use of AM as integrated formwork for construction, only few constructive experiments based on this technique have been documented. AM of formwork can be seen in the Batiprint printing process, though the material used is foam, making the formwork disposable. The case study presented in this paper is the first using method UHPC concrete to produce integrated formwork for an actual building project using the XtreeE 3D concrete printing system.

The aim of the present work is to shed a new light on the perspective of 3D concrete printing in the construction industry, specifically using the integrated formwork technique, by describing this project. With many new industrial players but not many largescale realisations yet, cement-based AM manufacturing appears to be at a critical point of development. The present paper seeks to discuss the industrial assimilation of these new construction techniques and the issues currently at stake in this matter. First, an 
introduction on designing structures for large-scale additive manufacturing is given. In Sect. 3, the concrete formwork 3D printing technique is presented, followed by the case study demonstrating the potential advantages of such a technique for the construction industry. Finally, conclusions are drawn regarding the results obtained in this work.

\section{Design for Additive Manufacturing}

Generating and modelling shapes for additive manufacturing follows specific rules, coming from both processing constraints, and functional objectives. According to [10], the concept of freeform previously used in the literature is not adequate nor sufficient for describing concrete 3D printing. For a given printing process and automation complexity, one can attain specific types of topologies within a given time-frame and performance criterion for the structure. Although out of the scope of the present paper, design conditions for large-scale additive manufacturing depend on many other parameters than just the properties of extruded cementitious materials; parameters such as the printing spatial resolution, overall size of parts to be printed, the environment, the presence of assembly steps, etc. A classification of such relationships between geometrical complexity, processing, and design is proposed in [7].

The processing constraints depend mostly on the fresh material properties in its viscous state, as well as early-age behaviour, in interaction with the building strategy and the stiffness of the structure being built. On the other hand, functional requirements will depend on the properties of the hardened material as well as the structural geometry for effective stiffness, and other functional properties such as thermal and sound insulation. See [10] for a geometrically induced thermal insulation case study. Both types of constraints must be considered at the design stage. Material properties of $3 \mathrm{D}$ printed concrete used by XtreeE, including in the case-study presented in this paper, are highlighted in [10] as well. More information on 3D printed concrete in general can be found in the very recent review published by [13].

Printing path generation is a critical step to be considered in early design phase. It is indeed the prime problem, embracing together machine, material and structural requirements. 3D-to-2D slicing, which is by far the most common method adopted in the context of 3D printing, yields planar layers of equal thickness built on top of each other. This approach is not optimal from a design and structural viewpoint as it will induce shifts when two consecutive layers have different sizes and limit the attainable geometries. In the context of 3D printing. Other approaches to tool-path generation have been developed, such as the tangential continuity method introduced in [10] to optimise the structure being built by creating layers of varying thickness. These layers exhibit a maximized surface area of contact between each other, hence stabilizing the overall structure. However, in the present case-study, as no other reliable software allowing the use of other methods existed yet, the first method was used.

\section{Concrete Formwork 3D Printing}

The process of large-scale concrete 3D printing developed by XtreeE has been mentioned previously in [10], the overall process is summarized in Fig. 1. 


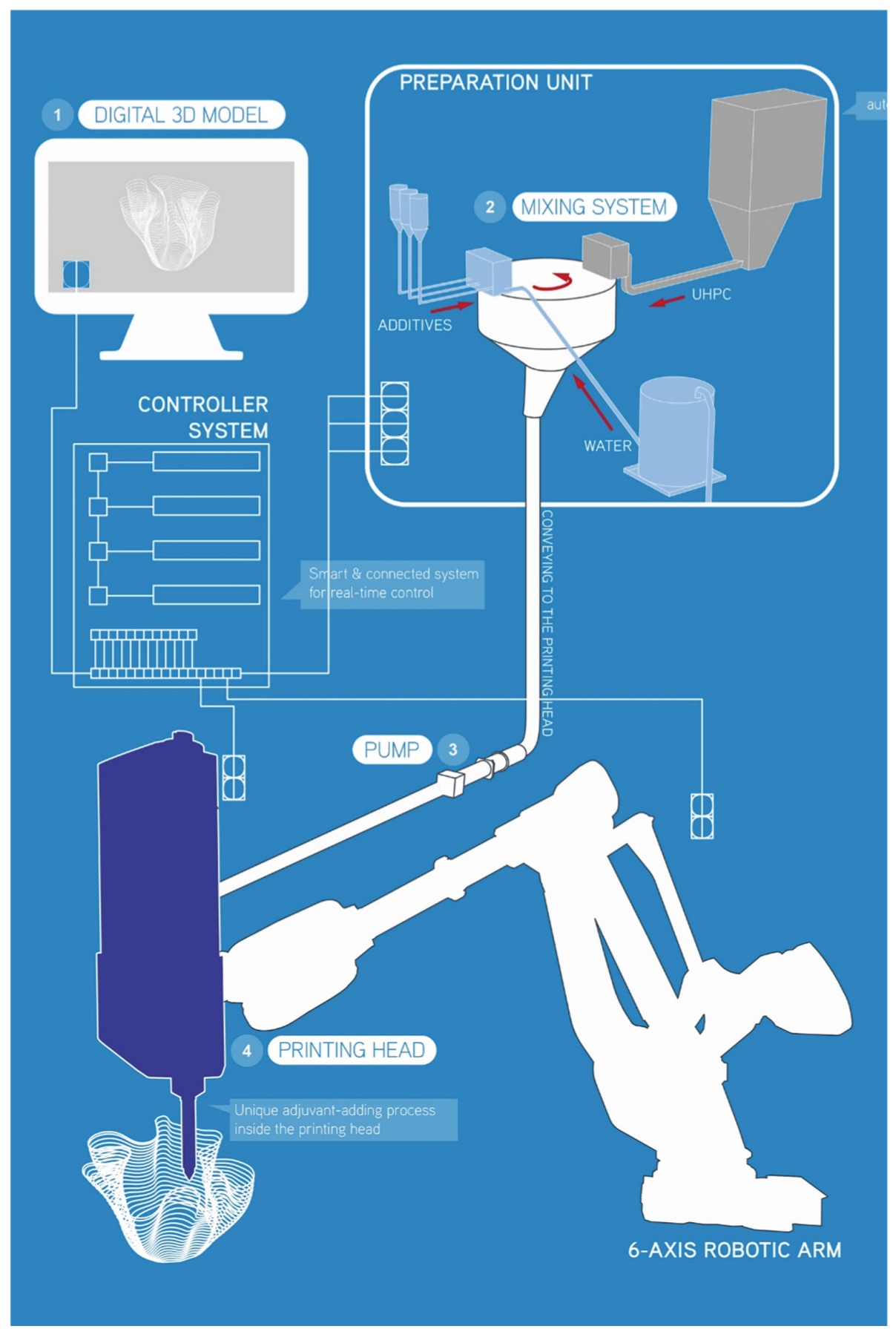

Fig. 1. Workflow of the large-scale concrete 3D printing process. 
Based on this process, a construction strategy can be derived for concrete formwork $3 \mathrm{D}$ printing. The principle consists in 3D printing the formwork necessary for casting another structural material such as ultra-high-performance concrete for fibre-reinforced concrete, or insulation material such as foamed concrete, as shown on Fig. 2. The printed formwork is left in-place and becomes a so-called lost formwork. An optimal trade-off must be considered from the early design steps as to the ratio of printed material within the built part, which can be critical for reaching economic viability. Depending on the application considered, concrete formwork 3D printing can be more efficient than either all-3D concrete printing, or traditional building techniques, from both an economic and/or building strategy viewpoint. This assertion is demonstrated in the next section on the Aix-en-Provence post case study.
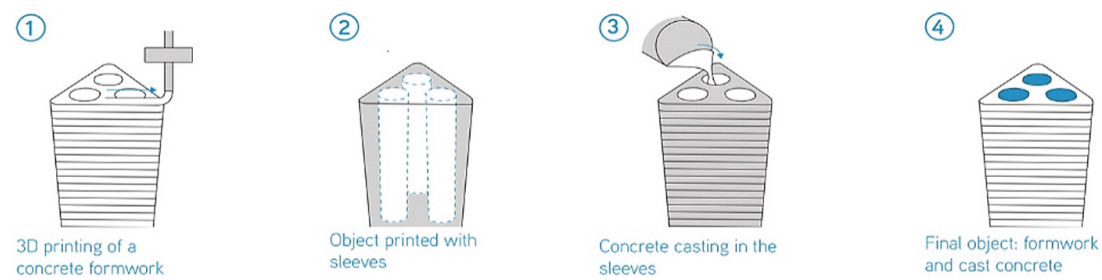

Fig. 2. Schematic view of the concrete formwork 3D printing.

\section{Pillar in Aix-en-Provence, France}

\subsection{Context}

This $4 \mathrm{~m}$-high freeform pillar is placed in the sports facilities of a school in Aix-enProvence, France. It supports a concrete awning covering part of the playground (Fig. 3). The sports facilities project was mandated by the Aix-Marseille Metropolis. The pillar, part of this larger project, was handled by the following people: Marc Dalibard as architect (also the architect for the whole sports facilities building), Artelia as structural engineering office, AD Concept as construction company, LafargeHolcim as material supplier and Fehr Architectural as UHPC concrete caster. For the construction of the pillar, the responsibilities of the actors were divided as follow: Marc Dalibard, as architect, was also the manager of the overall project, and defined the shape and placement of the pillar. Artelia, as structural engineer, supported XtreeE both during design and construction phases, and was tasked with defining the load case on which to base the topological optimization and verifying the strength and stability of the printed pillar in accordance with the load case. LafargeHolcim supplied a specific 3D print concrete, developed with XtreeE in an earlier collaboration and Fehr Architectural casted UHPC inside the pillar, a task requiring a specific licence. Each one of the key players supported XtreeE in the definition of the fabrication strategy adopted for the pillar, by providing input regarding their field of expertise. 


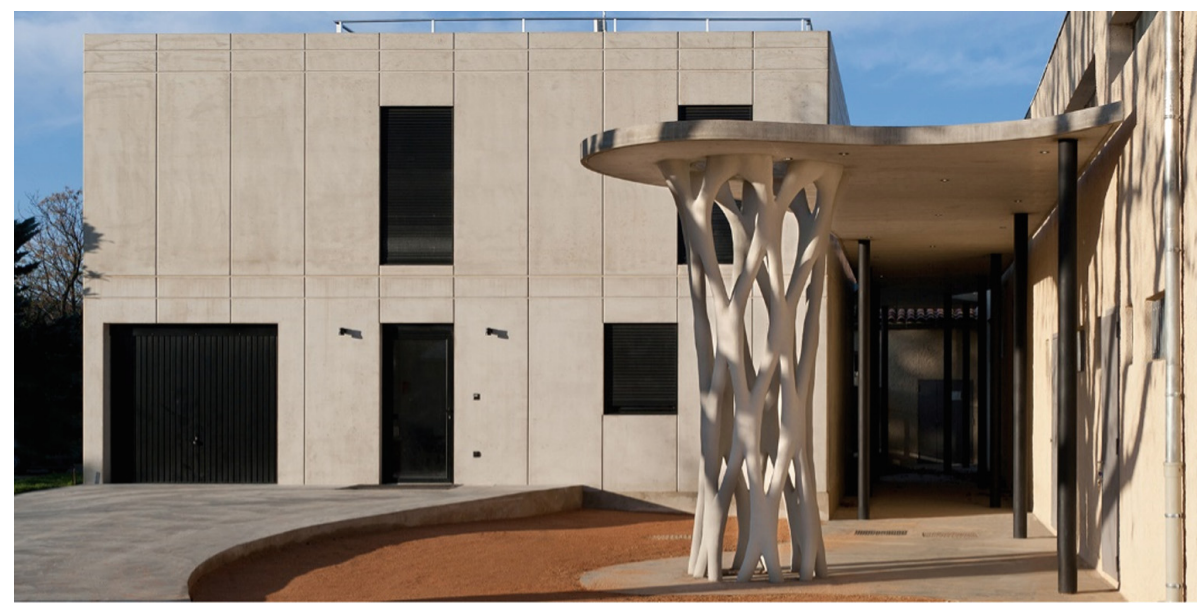

Fig. 3. Pillar in Aix-en-Provence, photo by Lisa Ricciotti.

XtreeE identified a fabrication strategy for the post and adapted the printing system developed earlier (presented in Sect. 3) according to the fabrication strategy and its requirements. During the design stages, XtreeE co-defined the load case with structural engineer Artelia and designed an exact shape for the pillar through structural design. In the fabrication stages, XtreeE coded the manufacturing files using HAL Robotics for the printing system and performed the manufacturing, before co-supervising the placing of the pillar on site with architect Marc Dalibard.

Although relying on the skills of well established players of the construction market and its various subgroups, it is interesting to note that the Aix-en-Provence pillar studied in this paper presents a new workflow between the stakeholders of the project. This new workflow is established due to the appearance of a new player, XtreeE. XtreeE plays in this case the roles of technical expert in 3D printing, giving advice for every step of the conception and manufacturing process, of designer of the final shape and of manufacturer for the $3 \mathrm{D}$ print elements. While the new industrial protagonists in the field of AM manufacturing for construction applications might not, in the future, play such polyvalent role in projects, the Aix-en-Provence pillar gives an example of the array of possible interventions, and therefore of the many changes that could be implemented, not only with AM, but also with various rising digital conception and manufacturing tools.

\subsection{Design}

In the initial project designed by architect Marc Dalibard, a complex truss-shaped pillar supporting the roof was already planned, as shown on Fig. 4. But though the idea of a complex truss-shaped pillar was featured, no viable design for the pillar existed at this stage of the project. XtreeE came in at this point and took over the design of the pillar, based on the sketches provided by the architect. 


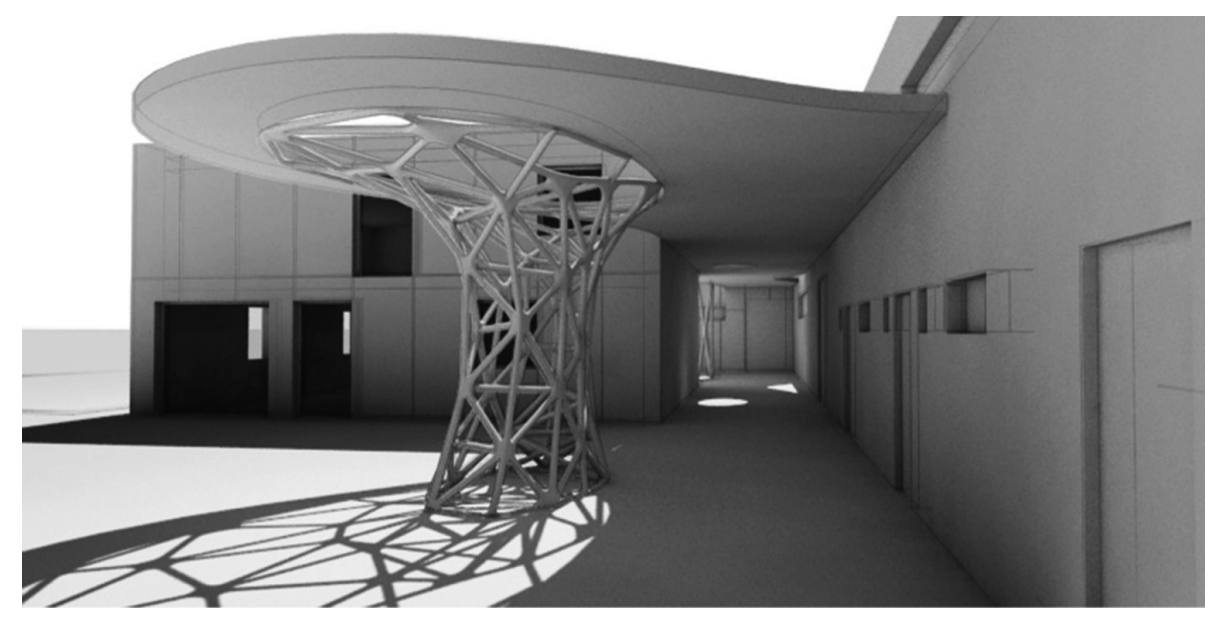

Fig. 4. Initial sketch for the pillar.

The design of the pillar is based as much on the formal intention highlighted in these sketches as on the constraints fixed by the building regulations in effect at the time and by the $3 \mathrm{D}$ printing manufacturing method.

As no building regulation existed regarding 3D print items integrated in buildings at the time of construction, and to stick to the projected schedule, the choice was made to use the lost formwork manufacturing method, as introduced in Sect. 3. Instead of having to validate the pillar and its manufacturing method by using an ATEx (Experimental technical appreciation), a long and expensive procedure for experimental construction in France, the lost formwork made it possible to rely on existing building regulations on UHPC concrete. Furthermore, having recourse to 3D printing technology for the fabrication of architectonic elements offers the possibility to build nonstandard geometries, with fine and curved elements. However, the complexity of those shapes proscribes implementing steel reinforcements inside. This impossibility, along with the fact that the shape of the pillar as designed by the architect had for main characteristic the slenderness of its parts, also called for the use of UHPC inside the formwork.

The critical design constraint for layer by layer extrusion techniques is the maximum inclination if the geometry. In the case of the Aix-en-Provence pillar, this issue was avoided by printing supports at the same time than the geometry to enable any angle for the parts of the truss. This has been commented in [7].

To define the precise shape of the pillar, we relied on an optimization method, to ensure an optimal use of matter in the truss by refining the limbs and taking into account the fabrication constraints as well as the wishes of the architects regarding the shape. The entire circular volume containing the pillar is used as research space for the truss to develop, and the applied load case included the weight of the concrete awning supported by the pillar as well as site-specific constraints (wind, etc.). The resulting final shape is shown on Fig. 5. A more thorough examination of the possibilities offered by topology optimization in the context of 3D concrete printing is available in [8]. 

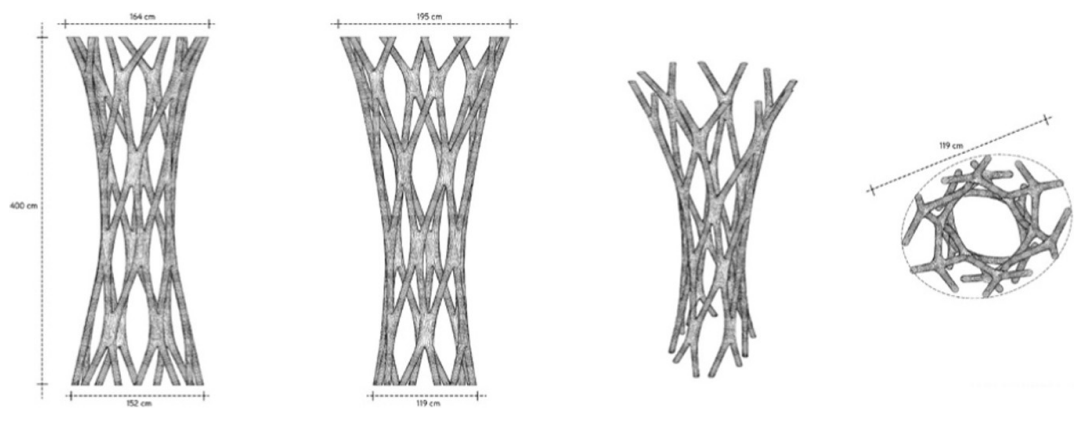

Fig. 5. Final design of the pillar after topology optimization.

Given the selected approach of lost formwork printing, the pillar is made of an outer shell that is 3D printed and later filled with UHPC. The pillar is divided in three smaller parts (cf. Fig. 6), both for transportation constraints and to reduce hydrostatic pressure when self-compacting concrete is casted inside. Each part is to be filled with concrete and then assembled together to form the whole element. During casting, metallic connectors are inserted in the concrete at each end of the parts to ensure reinforcement continuity of the construction joints. Finally, chemical glue is used to seal the connection.

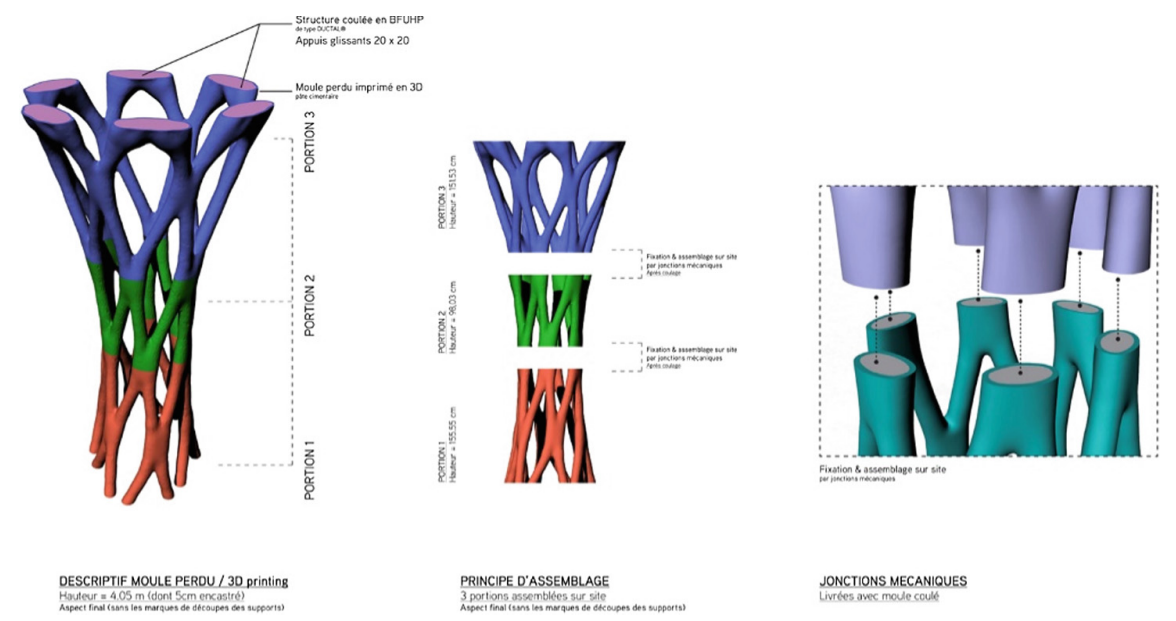

Fig. 6. Splitting and assembling principles for the 3D printed pillar system.

\subsection{Manufacturing}

Manufacturing of the pillar includes several stages: 3D printing the outer shell, at XtreeE headquarters in the south of Paris, France, casting the UHPC and integrating the connectors, at the Fehr Architectural production facility in Germany, and final 
assembly on site in Aix-en-Provence. 3D printing the outer shell inside the facility enables, like for UHPC casting, a precise control and monitoring of the environment, to ensure ideal temperature and humidity conditions for the concrete to behave as expected.

As a precaution, after running trials on smaller geometries similar to the pillar, it was decided to 3D print the formwork in four parts rather than three. The concrete formwork took $15 \mathrm{~h}$ to print in total, approximately $3 \mathrm{~h}$ and $45 \mathrm{~min}$ for each part of the post, with the former XtreeE printing system - adjustments made over the past year now make it faster. The printing of one of the parts is shown on Fig. 7. Setting time starts to occur after several minutes. Once the formwork was successfully 3D printed, an assembly trial, shown on Fig. 8, was conducted at our facility to ensure the results were as precise as expected before shipping the parts.

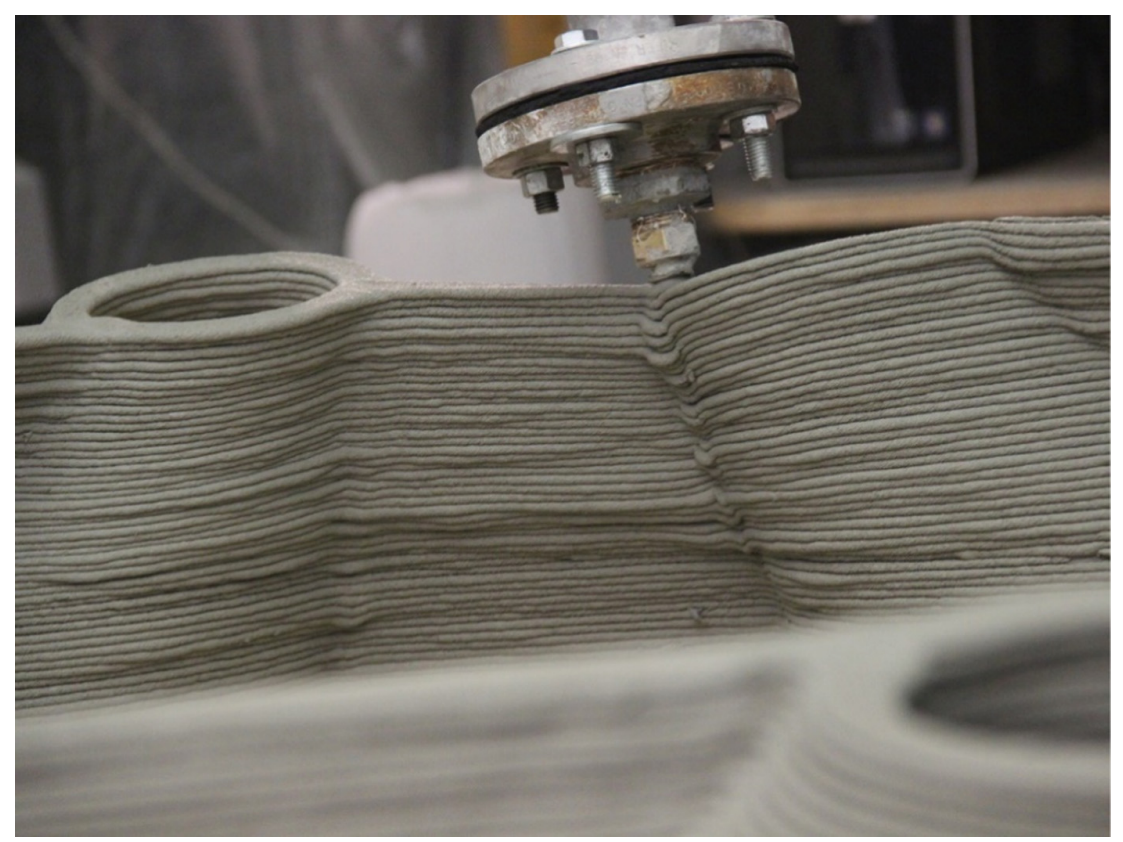

Fig. 7. Printing of one of the parts of the pillar's formwork.

The casting of UHPC in each part of the pillar was then operated by the team of Fehr Architectural. To resist the hydrostatic pressure resulting from the casting, supports printed with the pillar were left in place until the UHPC set, as shown on Fig. 9. The supports were then cut, as shown on Fig. 10, and the parts were shipped on site to Aix-en-Provence. The definitive assembly of the parts was performed there, before installing the pillar in place, with sliding supports on top. Finally, on request of the architect, the pillar was given a smooth finish by coating it to cover the line pattern specific to 3D printed objects. The difference of surface roughness is shown on Fig. 11. 


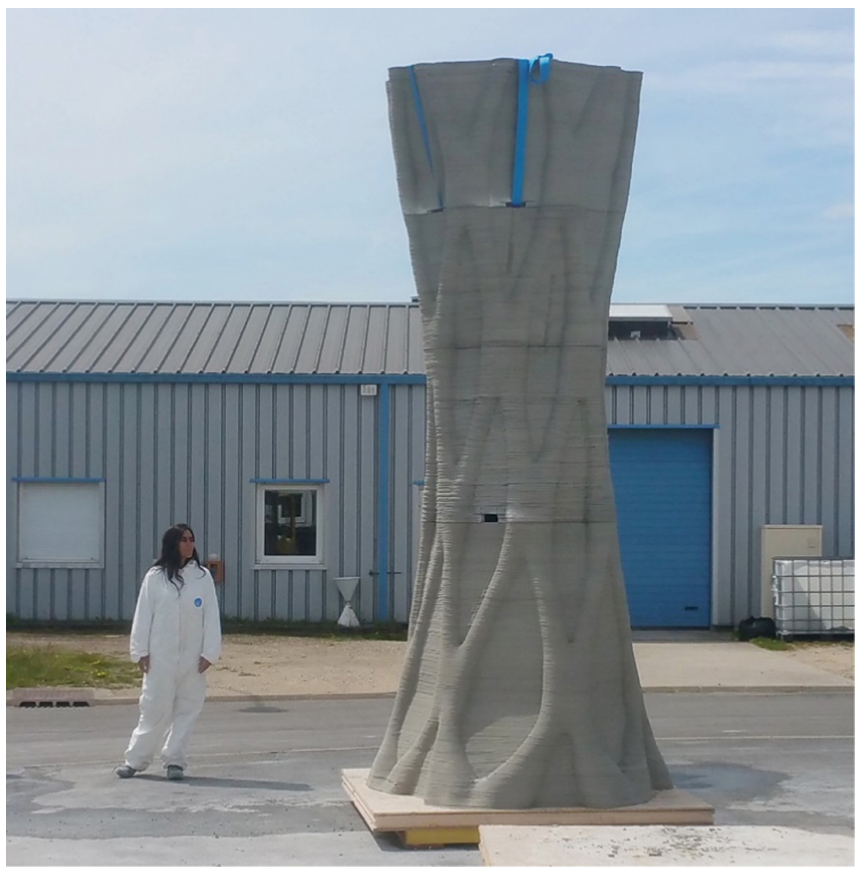

Fig. 8. Assembly trial after printing of the four parts.

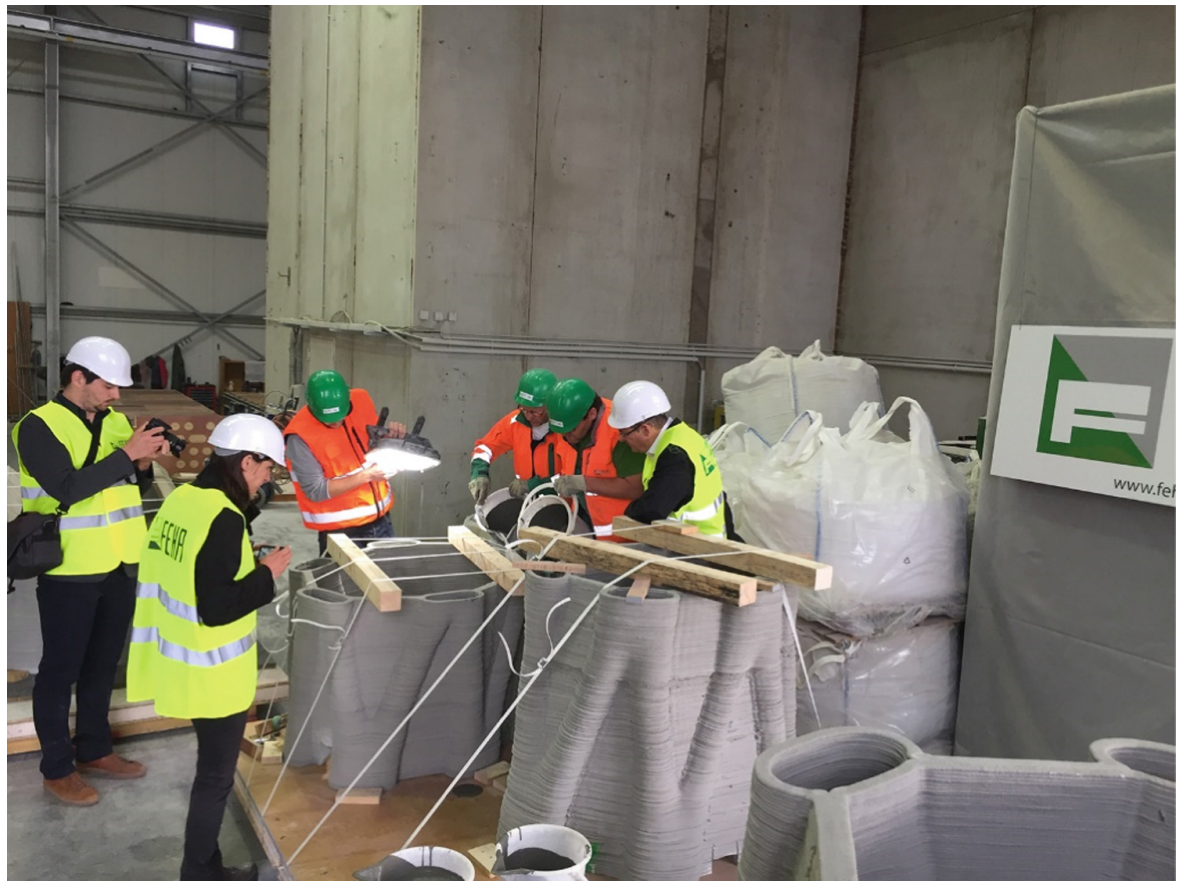

Fig. 9. UHPC casting inside the envelope, with supports left in place. 


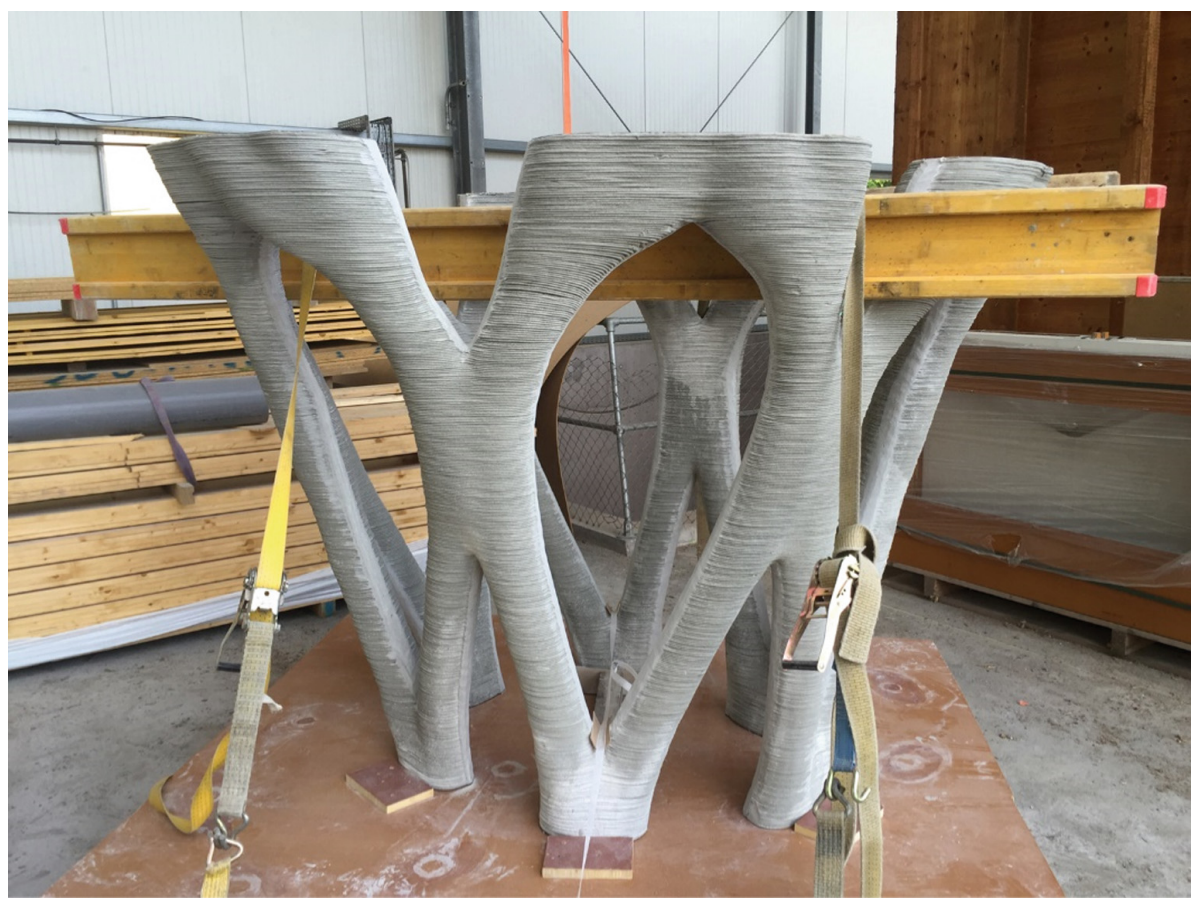

Fig. 10. Cast and lost formwork assembly from which the printing supports were cut.

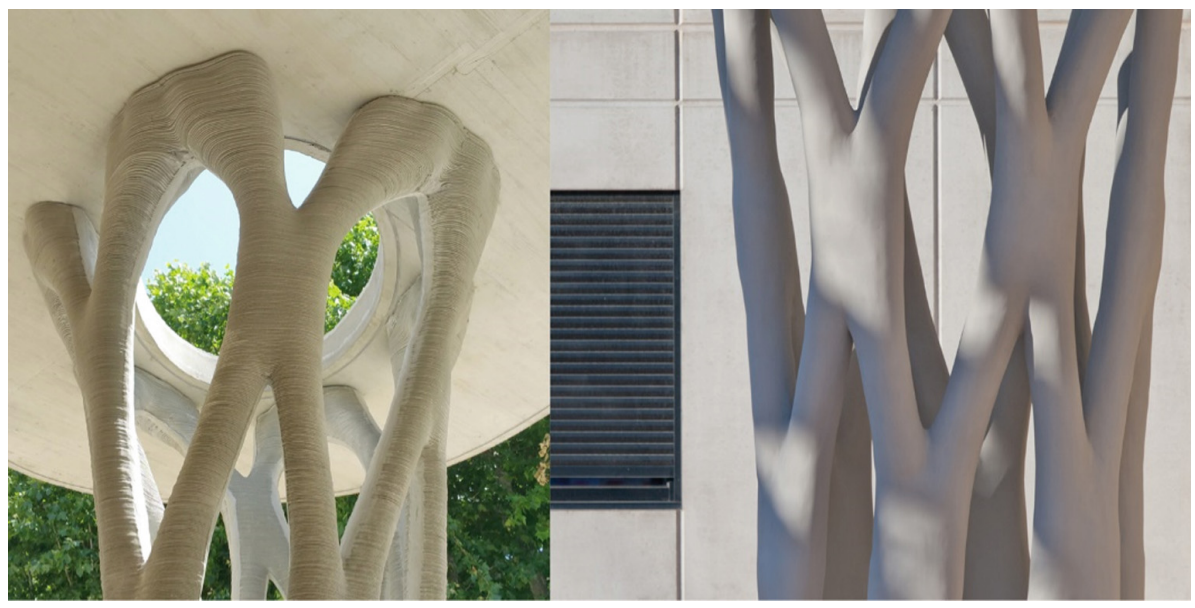

Fig. 11. Before (left) and after (right, photo by Lisa Ricciotti) surface smoothing through manual coating. 


\section{Conclusions and Outlook}

The various advantages of large-scale additive manufacturing of ultra-highperformance concrete, as well as the concrete formwork 3D printing technique, have been reviewed based on the analysis of the case study of a complex pillar part of an industrial construction projects in France, performed using the XtreeE 3D printing technology. A final significant element of comparison can be given by confronting the total production price of the Aix-en-Provence pillar to the total production price of a traditionally built complex pillar: a $62,5 \%$ total price gain is obtained, based on our information for the price of the Aix-en-Provence pillar, and quotes obtained for a traditional manufacturing. One of the main reason for this difference, on top of the gain identified on time, materials, and workforce, is the absence of a specific material and shaping for the mould, hence eliminated by using the lost formwork method. The multiple aspects of potential socio-economic gain for relying on additive manufacturing are three-fold: (1) materials saving by using the right amount of matter where needed, given that a topology optimization computational framework is available; (2) time saving by reducing the number of steps in the construction process, as well as being BIM-compatible for construction-planning strategies; (3) workforce saving by limiting on-site manual building steps, therefore enhancing safety on the construction site and implementing a new workflow between project stakeholders.

Although the lost formwork strategy allowed to get around experimental technical certification, further work should have to be conducted with certification authorities for the construction industry to define a legal and regulatory framework for 3D printed structures. The technological feats presented in this work are commercially available, but a legal framework and economic market are to be developed for the 3D printing technology to transfer into the mainstream construction industry.

Studying the conditions of design and fabrication of the Aix-en-Provence pillar also provides hints on possible improvements to the developed process, to push industrial assimilation forward.

Along with the paradigm shift of additive manufacturing comes the possibilities enabled by topology optimisation, which aims at attaining the most efficient structure geometrically possible for a given set of requirements. Optimality in terms of industrial design has become more and more critical due to scarcity of material resources and the need for lightweight structures.

A driving force for additive manufacturing is its ability to produce more complex $3 \mathrm{D}$ shapes in comparison to casting or subtractive processes. This complexity allows to design optimal structures based on topology optimisation techniques. One of the main current challenges is to modify optimisation algorithms to account for the additive manufacturing constraints, especially with regards to the processing parameters and structural stability while printing. A possible answer to these challenges would be to consider the multiphysics phenomenon aspect of 3D printing, which involves the elastic stability of the overall structure being built, the kinetics of hydration, the evolving viscoplasticity of fresh cement, the evolution of temperature within the printing environment, etc. As a matter of fact, all these physical problems, at multiple time and space scales, can be modelled on their own, but coupling them generates complexity and 
uncertainty regarding the process of 3D printing. Therefore, efforts should be concentrated on understanding and modelling the printing process in its multiple physical aspects, only then optimisation will be fully integrated with the processing, which would virtually change the way $3 \mathrm{D}$ printed structures are conceived today.

\section{References}

1. Bendsøe, M., Sigmund, O.: Topology Optimization. Springer, New York (2004)

2. Buswell, R.A., Soar, R., Gibb, A., Thorpe, A.: Freeform construction: mega-scale rapid manufacturing for construction. Autom. Constr. 16, 224-231 (2007)

3. Buswell, R.A., de Silva, W.R.L., Jones, S.Z., Dirrenberger, J.: 3D printing using concrete extrusion: a roadmap for research. Cem. Concr. Res. 107 (2018)

4. Cesaretti, G., Dini, E., Kestelier, X.D., Colla, V., Pambaguian, L.: Building components for an outpost on the lunar soil by means of a novel 3D printing technology. Acta Astronaut. 93, 430-450 (2014)

5. Crump, S.: Apparatus and method for creating three-dimensional objects US Patent US5340433A (1992)

6. Cui, C., Ohmori, H., Sasaki, M.: Computational morphogenesis of 3D structures by extended ESO method. J. Int. Assoc. Shell Spatial Struct. 44(1), 51-61 (2003)

7. Duballet, R., Baverel, O., Dirrenberger, J.: Classification of building systems for concrete 3D printing. Autom. Constr. 83, 247-258 (2017)

8. Duballet, R., Baverel, O., Dirrenberger, J.: Design of space truss based insulating walls for robotic fabrication in concrete. In: De Rycke, K., Gengnagel, C., Baverel, O., Burry, J., Mueller, C., Nguyen, M.M., Rahm, P., Thomsen, M.R. (eds.) Humanizing Digital Reality, Design Modelling Symposium 2017, pp. 453-461. Springer, Singapore (2017)

9. Duballet, R., Gosselin, C., Roux, P.: Additive manufacturing and multi-objective optimization of graded polystyrene aggregate concrete structures. In: Thomsen, M., Tamke, M., Gengnagel, C., Faircloth, B., Scheurer, F. (eds.) Modelling Behaviour, Design Modelling Symposium 2015, pp. 225-235. Springer, Cham (2015)

10. Gosselin, C., Duballet, R., Roux, P., Gaudillière, N., Dirrenberger, J., Morel, P.: Large-scale 3D printing of ultra-high performance concrete - a new processing route for architects and builders. Mater. Des. 100, 102-109 (2016)

11. Khoshnevis, B.: Automated construction by contour crafting- related robotics and information technologies. Autom. Constr. 13, 5-19 (2004)

12. Pegna, J.: Exploratory investigation of solid freeform construction. Autom. Constr. 5, 427-437 (1997)

13. Roussel, N.: Rheological requirements for printable concrete. Cem. Concr. Res. 107 (2018)

14. Sachs, E., Haggerty, J., Cima, M., Williams, P.: Three-dimensional printing techniques, US Patent US08045632 (1993)

15. Zhou, S., Li, Q.: Design of graded two-phase microstructures for tailored elasticity gradients. J. Mater. Sci. 43, 5157-5167 (2008) 